\title{
Sources identification of antibiotic pollution combining land use information and multivariate statistics
}

\author{
Jia Li • Haibo Zhang • Yongshan Chen • \\ Yongming Luo $\cdot$ Hua Zhang $\mathbb{D}$
}

Received: 14 December 2015 / Accepted: 16 June 2016/Published online: 23 June 2016

(C) Springer International Publishing Switzerland 2016

\begin{abstract}
To quantify the extent of antibiotic contamination and to identity the dominant pollutant sources in the Tiaoxi River Watershed, surface water samples were collected at eight locations and analyzed for four tetracyclines and three sulfonamides using ultraperformance liquid chromatography tandem mass spectrometry (UPLC-MS/MS). The observed maximum concentrations of tetracycline $\left(623 \mathrm{ng} \mathrm{L}^{-1}\right)$, oxytetracycline $\left(19,810 \mathrm{ng} \mathrm{L}^{-1}\right)$, and sulfamethoxazole (112 ng $\mathrm{L}^{-1}$ ) exceeded their corresponding Predicted No Effect Concentration (PNEC) values. In particular, high concentrations of antibiotics were observed in wet summer with heavy rainfall. The maximum concentrations of antibiotics appeared in the vicinity of intensive aquaculture areas. High-resolution land use data were used for identifying diffuse source of antibiotic pollution in the watershed. Significant correlations between tetracycline and developed $(r=0.93)$, tetracycline and barren $(r=0.87)$, oxytetracycline and barren $(r=0.82)$, and sulfadiazine and agricultural facilities $(r=0.71)$ were
\end{abstract}

J. Li $\cdot$ H. Zhang $(\bowtie) \cdot$ Y. Luo $\cdot$ H. Zhang $(\bowtie)$

Key Laboratory of Coastal Environmental Process and Ecology Remediation, Yantai Institute of Coastal Zone Research, Chinese Academy of Sciences, Yantai 264003, China

e-mail: hbzhang@yic.ac.cn

e-mail: hzhang@yic.ac.cn

J. Li

University of Chinese Academy of Sciences, Beijing, China

Y. Chen

Institute of Urban Environment, Chinese Academy of Sciences, Xiamen 361021, China observed. In addition, the density of aquaculture significantly correlated with doxycycline $(r=0.74)$ and oxytetracycline $(r=0.76)$, while the density of livestock significantly correlated with sulfadiazine $(r=0.71)$. Principle Component Analysis (PCA) indicated that doxycycline, tetracycline, oxytetracycline, and sulfamethoxazole were from aquaculture and domestic sources, whereas sulfadiazine and sulfamethazine were from livestock wastewater. Flood or drainage from aquaculture ponds was identified as a major source of antibiotics in the Tiaoxi watershed. A hot-spot map was created based on results of land use analysis and multivariable statistics, which provided an effective management tool of sources identification in watersheds with multiple diffuse sources of antibiotic pollution.

Keywords Antibiotics pollution · Land use - Source identification · Aquaculture

\section{Introduction}

Antibiotics are used as medicine for curing infectious diseases of human and animals (Moreno-Bondi et al. 2009; Kummerer 2009; Jiang et al. 2011; Galvidis et al. 2015). Tremendous amounts of antibiotics are consumed in China, with an annual usage approximately $2 \times 10^{5} \mathrm{t}$ (Luo et al. 2011). Although half-lives of most antibiotics are generally shorter than persistent organic pollutants (POPs), continuous or near-continuous release of antibiotics into the environment can result in pseudo-persistence and pose threats to ecosystem and 
human health. Studies on occurrence and distribution of antibiotics in rivers, lakes, and estuaries often show severe pollution in China. A large array of antibiotics was detected in water samples from Huangpu River (Jiang et al. 2011), Yellow River (Zhang et al. 2012b), Pearl River Estuary (Xu et al. 2013), and coastal water of the Bohai Bay (Zou et al. 2011) at relatively high concentrations. It is reported that 10 antibiotics showed relatively high ecological risk to relevant aquatic organisms in the Pearl River Delta (Xu et al. 2013).

The main sources of antibiotics in surface water are domestic pollution, waste water from livestock farming and drug manufactures, and drainage or flood from aquaculture ponds (Kummerer 2001; Thiele-Bruhn 2003; Kemper 2008; Zou et al. 2011; Zuccato et al. 2010; Larsson et al. 2007). Concentrations and isomers of antibiotics in surface water vary greatly among regions depending on antibiotic usage and consumption (Kolpin et al. 2002). The data of antibiotics in wastewater sources are generally unavailable or unreliable due to the lack of mandatory regulations in many countries. In addition, environmental factors such as landscape and climate can affect the transport of antibiotics from their sources to receiving water (Lee et al. 2007). Watershed rainfall-runoff process can also be a dominant factor on the variation of antibiotic concentration in surface water. Earlier studies often show that concentrations of antibiotics are higher in dry season than in wet season as a result of water dilution (Jiang et al. 2011; Luo et al. 2011; Xu et al. 2013). Complex interaction among various environmental factors pose great challenge for identifying antibiotic sources, especially in watersheds where loadings are dominated by diffusive sources that are difficult to identify and characterize. Land use analysis has been used in combination with multivariate statistics in source identification of PAHs (Sharma et al. 2007), heavy metal (Han et al. 2006), and pharmaceuticals (Vazquez-Roig et al. 2012). However, few studies have been carried out to identify the dominant sources of antibiotics in watersheds with complex land use patterns.

In this study, we characterized seasonal and spatial variation of antibiotics (doxycycline (DOC), tetracycline (TC), oxytetracycline (OTC), chlortetracycline (CTC), sulfadiazine (SDZ), sulfamethoxazole (SMZ), and sulfamethazine (SMX)) pollution in a watershed with intensive urban, agriculture, and aquaculture activities. Source identification was carried out using land use analysis and multi-variable statistics as a basis for effective prevention and management of antibiotics pollution. The objective is to develop a method to identify the major sources of antibiotics in watershed where discharge data are not available and to create a hotspot map for monitoring and management purposes.

\section{Materials and methods}

Study area description

The Tiaoxi watershed is located in northwest Zhejiang Province, East China, and has an area approximately $5800 \mathrm{~km}^{2}$. The mainstem of Tiaoxi is formed through the confluence of East Tiaoxi and West Tiaoxi in Huzhou and flow into Taihu Lake. Approximately 5.3 million people reside in the Tiaoxi watershed and most of the population is in the middle and lower basins. Predominate land use contain woodland, farmland, residential area, and aquaculture pond (Fig. 1). Animal husbandry and aquatic farming are intensive in the lower basin.

The Tiaoxi watershed has a subtropical humid monsoon climate. Precipitation is frequent and mainly concentrated in June and July. The average annual rainfall is $1460 \mathrm{~mm}$, and heavy rainstorm often occurs in wet season. The rainfall data from 2008 to 2009 are illustrated in Fig. 2. To enhance flood control and water storage, gate dams have been built on East Tiaoxi River and West Tiaoxi River as well as their tributaries.

\section{Sample collection and preparation}

A total of 23 surface water samples were collected from eight sites (Fig. 1) in the Tiaoxi watershed in September 2008, March 2009, and June 2010, respectively. Water samples were collected into brown bottle and stored in dark at $4{ }^{\circ} \mathrm{C}$ until analysis. Before detection, the water samples were filtered through $0.45 \mu \mathrm{m}$ cellulose acetate membranes. Then $1 \mathrm{~L}$ water sample was acidified to $\mathrm{pH}<3.0$, followed by addition of $0.5 \mathrm{~g}$ disodium ethylenediaminetetraacetic acid $\left(\mathrm{Na}_{2}\right.$ EDTA). The pretreated water sample was concentrated by passing through the Oasis HLB cartridge at a flow rate of $3.0 \mathrm{~mL} \mathrm{~min}{ }^{-1}$. The HLB cartridge has been preconditioned with $10 \mathrm{~mL}$ methanol and $10 \mathrm{~mL}$ ultrapure water with a flow rate of approximately $5.0 \mathrm{~mL} \mathrm{~min}{ }^{-1}$ before being used. After the water had passed through the combined cartridges, the HLB 


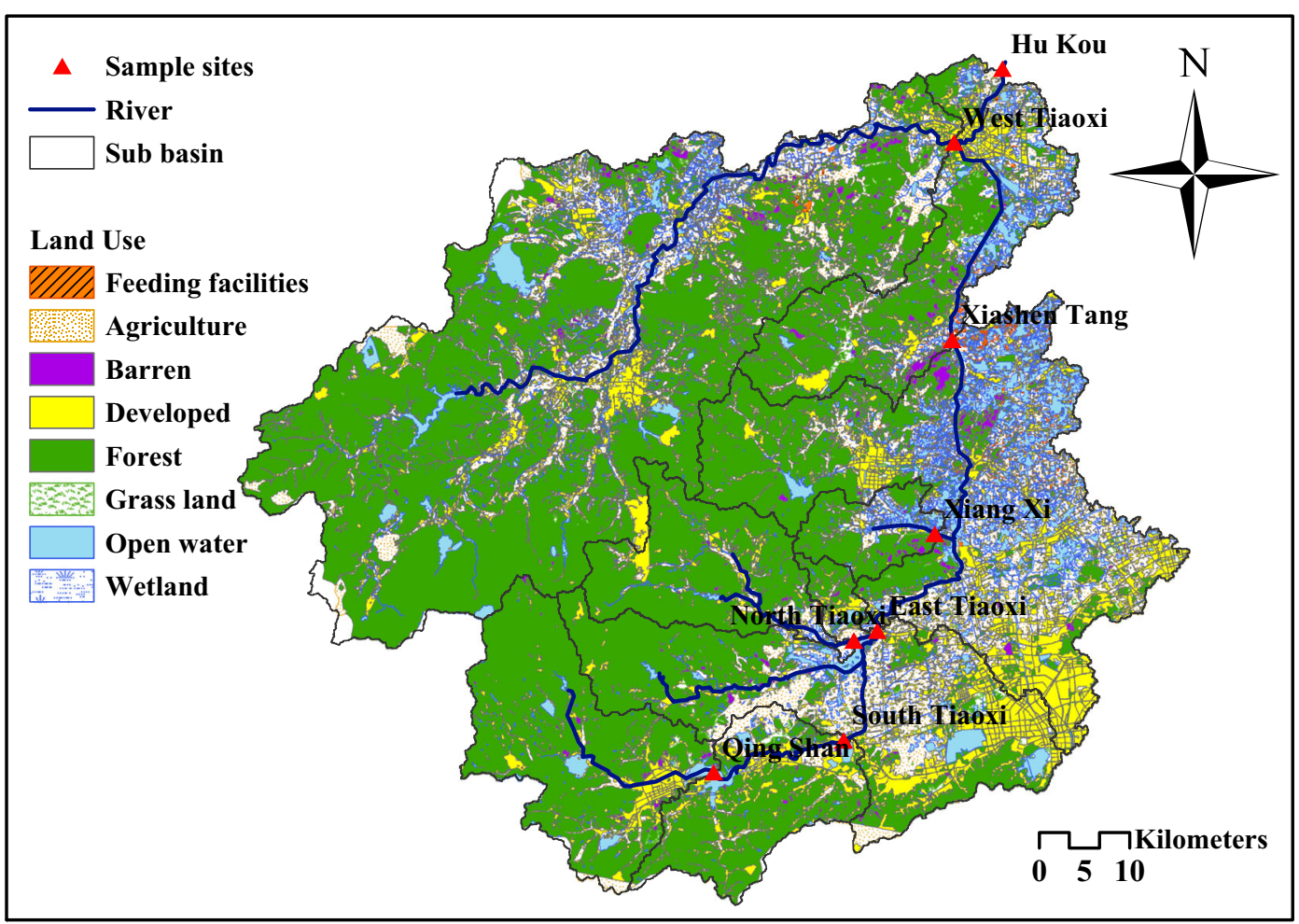

Fig. 1 Map of the Tiaoxi watershed showing the sampling sites and land use types

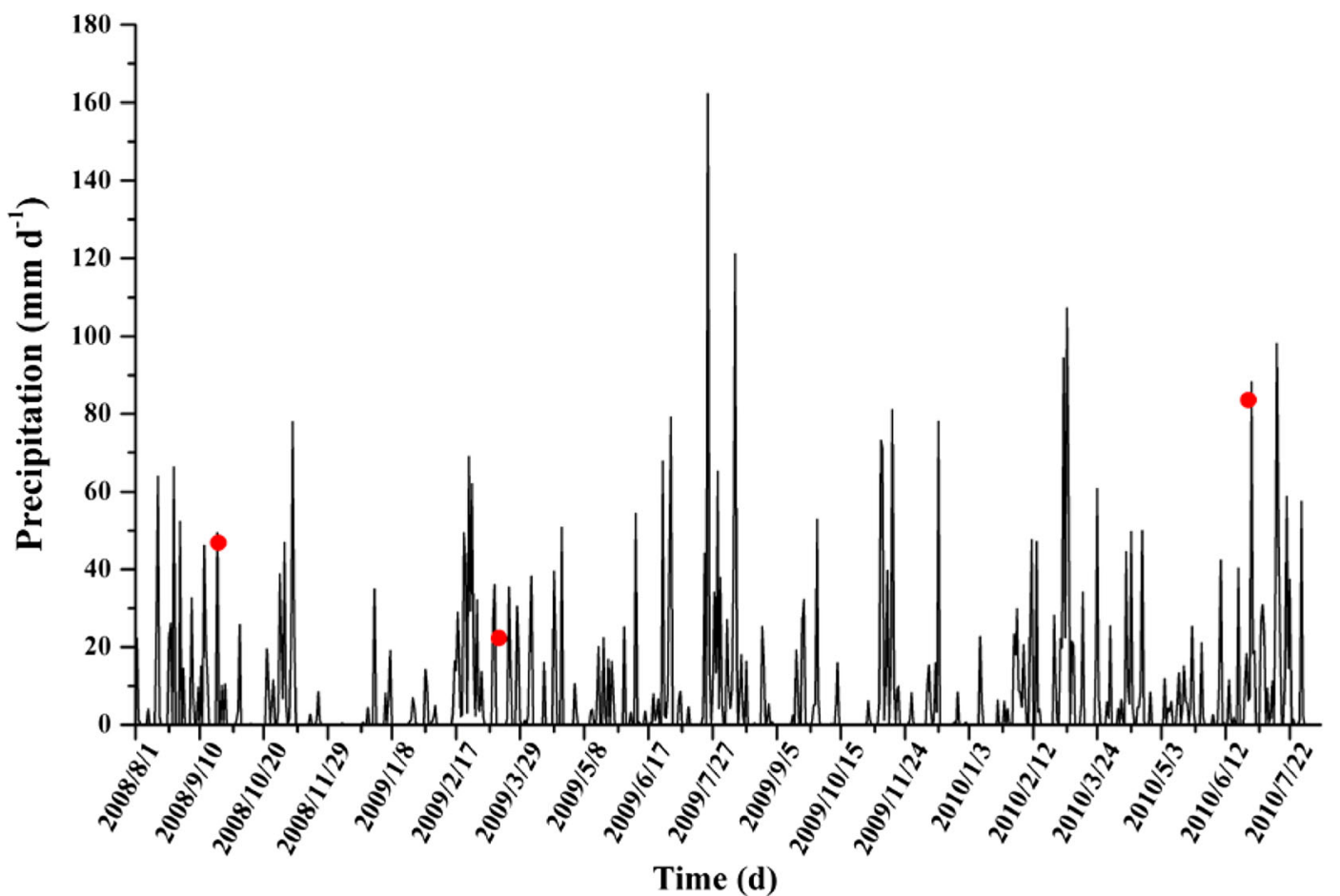

Fig. 2 Daily rainfall from August 2008 to July 2010. Red dots represent sampling dates. Rainfall data was obtained from weather station in Zhejiang Province 
cartridge was rinsed with $10 \mathrm{ml}$ of ultra-pure water and drying under nitrogen gas for $30 \mathrm{~min}$ at a flow rate of 2.0-4.0 mL $\mathrm{min}^{-1}$. Then each cartridge was eluted sequentially with $2.0 \mathrm{~mL}$ methanol (containing $0.1 \%$ $v / v$ formic acid) and $8 \mathrm{~mL}$ methanol with formic acid at a rate of $<3.0 \mathrm{~mL} \mathrm{~min}^{-1}$. The analytes were collected in a $15 \mathrm{~mL}$ brown glass vial and the volume was reduced to approximately $2.0 \mathrm{~mL}$ by purging with nitrogen. Ten microliter of ${ }^{13} \mathrm{C}_{3}$-caffeine $\left(1.0 \mathrm{mg} \mathrm{L}^{-1}\right)$ was added into the eluent as an internal standard, and the final volume in each vial was adjusted to $1.0 \mathrm{~mL}$ accurately with methanol/formic acid for UPLC-MS/MS analysis.

\section{UPLC-MS/MS analysis}

The analytes were analyzed by ultra-performance liquid chromatography (UPLC)-electrospray ionization tandem mass spectrometry with TQ detector (Acquity, Waters Corp., Milford, MA). The samples were separate on a Waters Acquity UPLC BEH C18 column $(1.7 \mu \mathrm{m}$, $2.0 \times 100 \mathrm{~mm})$ at a constant temperature of $30^{\circ} \mathrm{C}$. Mobile phase A was water (containing $0.1 \%$ formic acid), and $\mathrm{B}$ was methanol (containing $0.1 \%$ formic acid) for the separation of antibiotics. The gradient elution program is described as following: started at $90 \% \mathrm{~A}, 0-2 \mathrm{~min}$ linear gradient to $80 \% \mathrm{~A}, 2-7 \mathrm{~min}$ $20 \%$ A, 7-10 min linear gradient to $10 \%$ A, then eluent was brought to $100 \% \mathrm{~B}$ and maintained for $10 \mathrm{~min}$. The total flow rate was $0.3 \mathrm{~mL} \mathrm{~min}^{-1}$ and the sample injection volume was $5 \mu \mathrm{L}$. A triple quadripole mass spectrometer (Acquity, Waters Corp., Milford, MA) set in positive electrospray ionization ( $\mathrm{ESI}+$ ) mode was used for the detection and identification of the targeted antibiotics. Collection and treatment of data were performed by Masslynx 4.0 software (Thermo Electron Corp., Waltham, MA). MS/MS was operated at unit resolution in multiple reactions monitoring (MRM) mode. Source conditions were optimized as follows: spray voltage $+4000 \mathrm{~V}$, transfer capillary temperature $290{ }^{\circ} \mathrm{C}$, and argon were used as collision gas at a pressure of 1.0 mTorr. Determination was performed in selected reactions monitoring mode using the two most intense and specific fragment ions with a scan width of $0.06 \mathrm{~s}$. Detail of the analysis information can be found in our previous study (Chen et al. 2012). Internal standard method was applied to quantify antibiotics in the sample by comparing the peak area of the sum of the two monitored product ions of the target compounds with the internal standard of ${ }^{13} \mathrm{C}_{3}$-caffeine.
Method validation

A recovery study for surface water was conducted by spiking a concentration $\left(50 \mathrm{ng} \mathrm{L}^{-1}\right)$ of the target antibiotics into ultra-pure water prior to extraction. Average recovery of the antibiotics was in the range of 75.5 to $88.9 \%$. Limit of quantification (LOQ) was calculated by a statistical method using student's $t$ variate. LOQ of the analysis was in the range of 0.1 to $1.0 \mathrm{ng} \mathrm{L}^{-1}$.

Spatial analysis

Spatial analysis was conducted to calculate the land area contributing runoff to each sampling location. SRTM DEM data was obtained from the USGS in the form of 1 arc sec resolution geographic grids in the WGS84 horizontal and EGM96 vertical reference systems. The entire watershed was delineated into eight sub-watersheds with each sampling site as the outlet (Kang et al. 2010). Land use data obtained from the Institute of Geographic Sciences and natural resources research, CAS were merged into eight categories: (agriculture, forest, grassland, developed, feeding facilities, open water, barren, and wetlands) and displayed in Fig. 1. Area percentages of eight land use types in each sub-watershed were calculated using ArcGIS 9.3. The density of population, livestock, poultry, and aquaculture in each county of Tiaoxi watershed was extracted from statistical yearbook of Hangzhou and Huzhou. The density values were allocated to eight sub-watersheds using an area-average approach (Table 1).

\section{Statistical analysis}

To explore the relationship between antibiotic concentrations and environmental variables, correlation analysis was conducted using Spearman rank correlation. Antibiotic concentration, area percentage of eight land use types, estimated density of population, livestock, poultry, and aquaculture was included in correlation analysis and performed on three sampling events. Principle component analysis (PCA) was conducted on concentrations of seven kinds of antibiotics using SPSS19.0 with the minimum number of factors (Sofowote et al. 2008). The principle components with eigenvalues greater than 1 were extracted. 


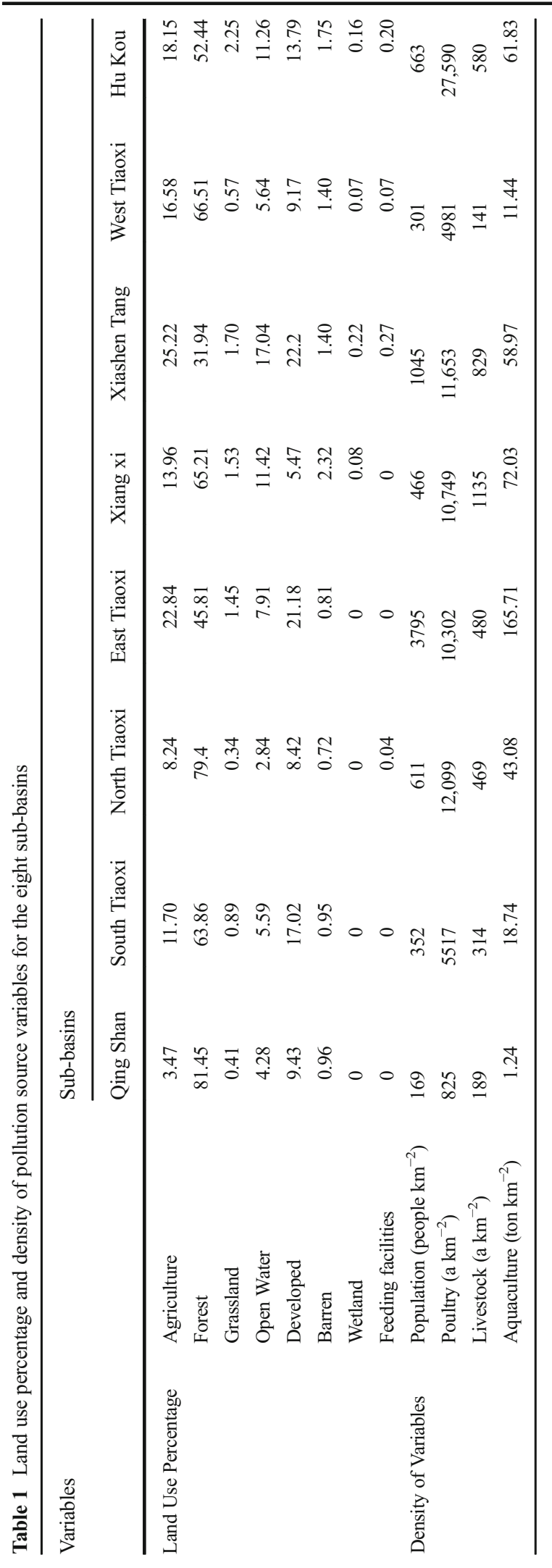

\section{Results and discussion}

Occurrence of target antibiotics in the Tiaoxi watershed

All seven kinds of antibiotics were detected at eight sites for three sampling events except a missing sample in West Tiaoxi in September, 2008 (Fig. 3). Concentrations of most detected antibiotics were in nanogram per liter level, except DOC and OTC in June, 2010 with peak concentrations up to microgram per liter level. Antibiotic concentrations in the same order of magnitudes were detected in the rivers of Jiangsu province (Wei et al. 2011). The three sulfonamides were detected with higher frequency, which was consistent with the conservative nature of sulfonamides in aquatic environment (Luo et al. 2011). Concentrations of TC, OTC, and SMX exceeded their PNEC values (Table 2), which indicated potential ecological toxicity of the antibiotics to aquatic organisms in Tiaoxi River.

Temporal and spatial distribution of antibiotics

As shown in Table 2, the measured concentrations of all antibiotics showed significant seasonal variations. Maximum concentrations of all antibiotics except CTC appeared in June. Secondary highest concentrations of DOC, OTC, and SMX appeared in September, while that of TC, SDZ, and SMZ showed in March. Rainfall amounts in June were larger than that in September and in March (Fig. 2). This indicated that antibiotics contamination in wet season was more serious than in dry season in the Tiaoxi watershed. This result was inconsistent with the studies conducted in Huangpu River (Jiang et al. 2011) and Haihe River (Luo et al. 2011), where higher concentrations of antibiotics in water sample were detected in dry season. A possible explanation was that point source pollution was dominant in Huangpu River and Haihe River, and water dilution had a great impact on concentrations of antibiotics in water samples. In contrast, the dominant source of antibiotics in the Tiaoxi watershed was nonpoint source. In wet season, large amounts of antibiotics flowed into the Tiaoxi River with the flood or drainage.

Among the eight sampling locations, East Tiaoxi and Xiang Xi were most polluted with all seven kinds of antibiotics detected at high concentrations (Fig. 3). All the target antibiotics can be detected in water samples 


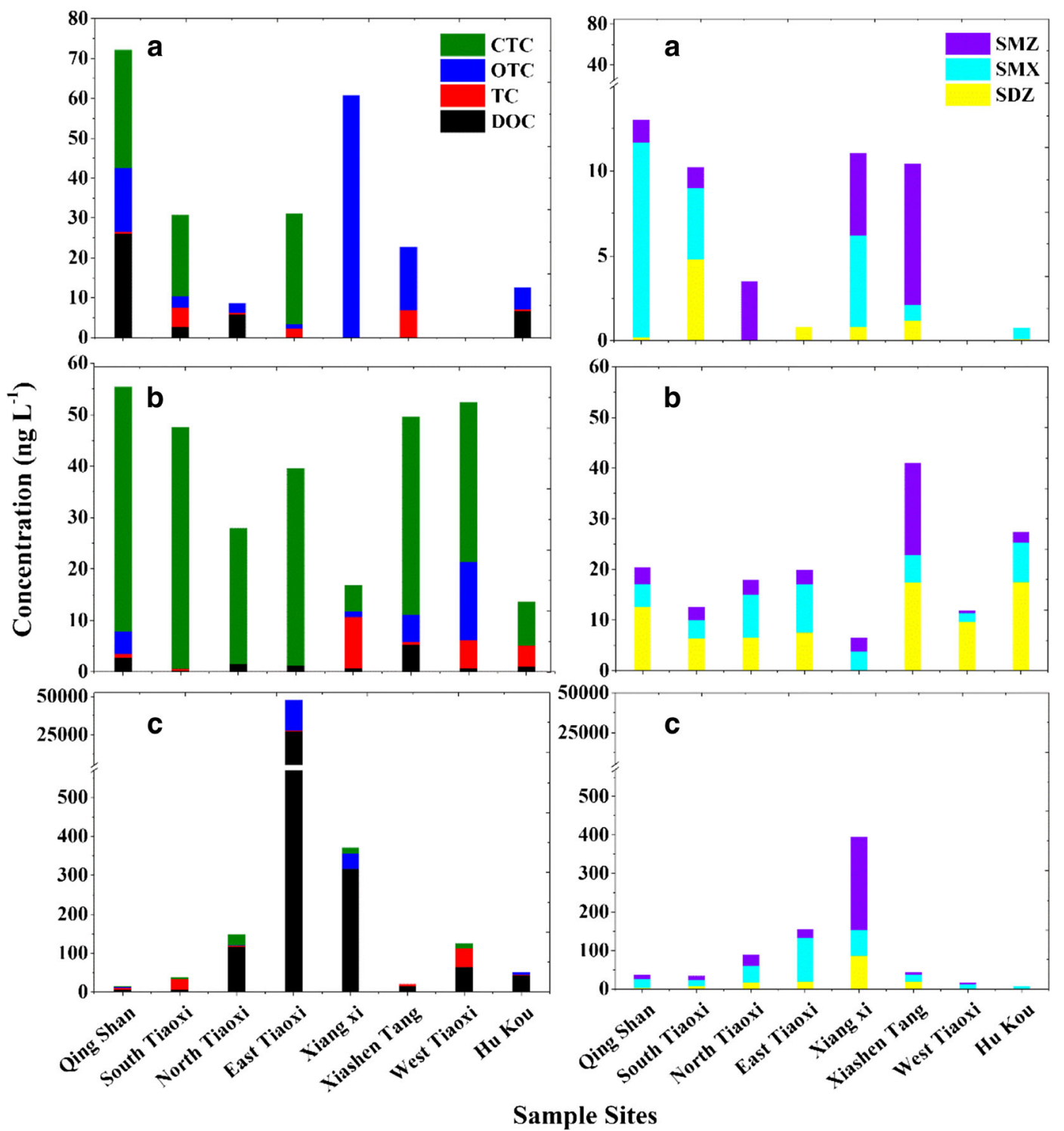

Fig. 3 Concentrations of tetracyclines (left) and sulfonamides (right) at seven sample sites of the Tiaoxi watershed. a September, 2008; b March, 2009; c June, 2010

from Qing Shan station at all three events with relatively lower concentration. The reason might be that main function of this reservoir was flood control, and it can act as sink for antibiotics. Very high concentrations of DOC $\left(27,166 \mathrm{ng} \mathrm{L}^{-1}\right)$, TC $\left(623 \mathrm{ng} \mathrm{L}^{-1}\right)$, and OTC $\left(19,810 \mathrm{ng} \mathrm{L}^{-1}\right)$ were detected in East Tiaoxi, where the density of aquaculture was the most intensive in the Tiaoxi watershed (Table 1). Antibiotics concentrations did not show clear trend from upstream to downstream, which indicated that diffusive non-point pollution sources were more influential on the Tiaoxi River.

\section{Correlation with land use types}

The results of spearman rank correlation analysis were showed in Table 3. TC exhibited a significant positive correlation with area of developed in September $(r=0.93)$ and barren land in March $(r=0.87)$. OTC significantly correlated with area of barren land in September $(r=0.82)$ and SDZ significantly correlated with area of feeding facilities in March $(r=0.71)$. In our study, the land of public buildings, land used for industrial, and residential land was defined as "developed". In 
Table 2 Concentrations of antibiotics in water samples collected from Tiaoxi River in comparison with Predicted No Effect Concentration (PNEC) values

\begin{tabular}{|c|c|c|c|c|c|}
\hline Antibiotics & $\begin{array}{l}\text { PNEC } \\
\left(\mathrm{ng} \mathrm{L}^{-1}\right)\end{array}$ & $\begin{array}{l}\text { Variables } \\
\left(n g \mathrm{~L}^{-1}\right)\end{array}$ & $\begin{array}{l}\text { Sampling time } \\
\text { 2008-2009 }\end{array}$ & $\begin{array}{l}\text { Sampling time } \\
\text { 2009-2003 }\end{array}$ & $\begin{array}{l}\text { Sampling time } \\
\text { 2010-2006 }\end{array}$ \\
\hline \multirow[t]{3}{*}{ Doxycycline (DOC) } & \multirow[t]{3}{*}{-} & Range & $\mathrm{Nd}-26.00$ & $0.26-5.28$ & $5.83-27,166.41$ \\
\hline & & Mean & 10.29 & 1.68 & 3467.06 \\
\hline & & Median & 6.25 & 1.10 & 54.12 \\
\hline \multirow[t]{3}{*}{ Tetracycline (TC) } & \multirow[t]{3}{*}{$90^{\mathrm{a}}$} & Range & Nd-6.90 & Nd-10.04 & Nd-623.43 \\
\hline & & Mean & 2.56 & 3.53 & 102.16 \\
\hline & & Median & 1.45 & 2.39 & 5.98 \\
\hline \multirow[t]{3}{*}{ Oxytetracycline (OTC) } & \multirow[t]{3}{*}{$207^{\mathrm{b}}$} & Range & $0.5-60.84$ & nd-15.24 & Nd-19,809.81 \\
\hline & & Mean & 14.90 & 6.46 & 3971.41 \\
\hline & & Median & 5.49 & 4.77 & 5.74 \\
\hline \multirow{3}{*}{$\begin{array}{l}\text { Chlortetracycline } \\
\text { (CTC) }\end{array}$} & \multirow[t]{3}{*}{$50^{\mathrm{a}}$} & Range & Nd-29.60 & $5.06-47.52$ & $\mathrm{Nd}-27.40$ \\
\hline & & Mean & 25.91 & 30.30 & 13.75 \\
\hline & & Median & 27.80 & 34.68 & 13.31 \\
\hline \multirow[t]{3}{*}{ Sulfadiazine (SDZ) } & \multirow[t]{3}{*}{$2200^{\mathrm{c}}$} & Range & $\mathrm{Nd}-4.82$ & Nd-17.54 & Nd-86.72 \\
\hline & & Mean & 1.33 & 11.12 & 22.34 \\
\hline & & Median & 0.82 & 9.62 & 17.20 \\
\hline \multirow{3}{*}{$\begin{array}{l}\text { Sulfamethoxazole } \\
\text { (SMX) }\end{array}$} & \multirow[t]{3}{*}{$27^{\mathrm{d}}$} & Range & Nd-11.50 & $1.74-9.58$ & $6.58-112.59$ \\
\hline & & Mean & 22.61 & 5.61 & 37.32 \\
\hline & & Median & 4.18 & 4.93 & 20.27 \\
\hline \multirow[t]{3}{*}{ Sulfamethazine (SMZ) } & \multirow[t]{3}{*}{-} & Range & Nd-8.30 & $0.50-18.16$ & $\mathrm{Nd}-241.04$ \\
\hline & & Mean & 3.83 & 4.32 & 46.10 \\
\hline & & Median & 3.50 & 2.68 & 10.84 \\
\hline
\end{tabular}

Nd not detected

${ }^{\mathrm{a}}$ (Halling-Sorensen et al. 2000)

${ }^{\mathrm{b}}$ (Lutzhoft et al. 1999)

c (Eguchi et al. 2004)

d (Ferrari et al. 2004)

these areas, intensive human activities may release antibiotics from pharmaceutical sources. It was observed that in some developed regions, antibiotics used in human medicine were the major sources of antibiotics in the aquatic environment (Wiegel et al. 2004). Therefore, the significant positive correlation between TC and developed area indicated that human sources might be a major contributor of TC. Studies have suggested that antibiotics in soil can be released into surface water through overland flow (Burkhardt et al. 2005; Kreuzig et al. 2005; Kay et al. 2005; Davis et al. 2006; Kim et al. 2010). In barren land, the antibiotics attached to soil particles were easily transported to the river because of the lack of vegetation cover (Jent et al. 2013). It was not surprising to see that barren land would exhibit a positive correlation with the concentrations of TC and OTC. Animal feeding facilities land refer to land served as the houses of the livestock and poultry breeding as well as aquaculture production facilities. Antibiotic concentrations near animal feeding facilities, which included livestock, poultry breeding, and aquaculture production facilities, were normally very high and entered the watershed via surface runoff, which were highly correlated with land use.

Correlation with potential sources

Correlation coefficients between antibiotics concentrations and the densities of pollution sources are given in Table 3. Concentrations of DOC and OTC were significantly correlated with density of aquaculture $(r=0.74$, 0.76 , respectively) for June 2010 sampling event. As 


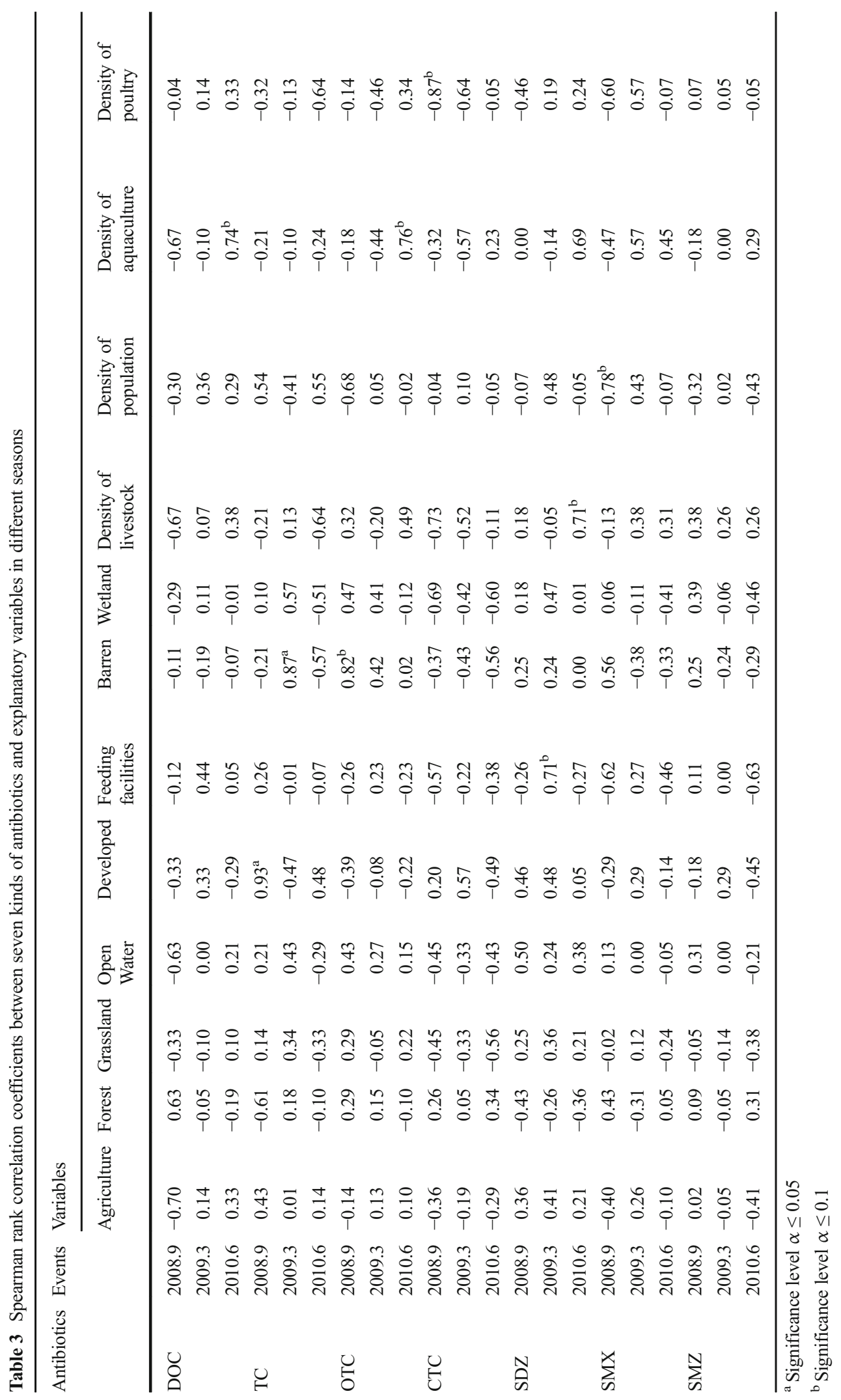


shown in Fig. 3, the peak concentrations of DOC and OTC all appeared in East Tiaoxi, where the aquaculture was intensive. Corresponding to this observation was these two antibiotics showed significantly positive correlations with aquaculture. SMX was negatively correlated with population, but it showed positive correlations with livestock and aquaculture in March and June. Therefore, we suggest that the major source of DOC, OTC, and SMX was aquaculture ponds in the Tiaoxi watershed. Although there were no significant correlations between TC and pollution sources, its positive correlation with developed area indicated that the main sources of TC were domestic pollution. SDZ and SMZ might mainly from animal husbandry because SDZ was significantly correlated with livestock. CTC did not exhibit any significant positive correlation with our explanatory variables, which indicate unaccounted sources might responsible for CTC. Concentrations of SDZ in June was significantly correlated with density of livestock $(r=0.71)$. It was consistent with the significant correlation between SDZ and area of animal feeding facilities.

\section{Source identification analysis}

PCA was performed to further identify the predominant pollution sources. The concentrations of antibiotics under the limit of detection (LOD) were recorded as half of the LOD values. Three principle components were extracted after varimax rotation, accounting for approximately $98 \%$ of the total variance (Table 4). The first component was responsible for $52.3 \%$ of the total

Table 4 Rotated component matrix from principle component analysis (PCA) of seven kinds of antibiotics (values $>0.8$ are highlighted)

\begin{tabular}{lrrr}
\hline Antibiotics & \multicolumn{3}{c}{ Principle components } \\
\cline { 2 - 4 } & 1 & 2 & 3 \\
\hline DC & 0.997 & 0.025 & 0.034 \\
TC & 0.997 & 0.003 & 0.013 \\
OTC & 0.997 & 0.015 & 0.034 \\
CTC & 0.033 & 0.022 & 0.999 \\
SDZ & 0.099 & 0.978 & 0.078 \\
SMX & 0.818 & 0.526 & -0.006 \\
SMZ & 0.010 & 0.986 & -0.043 \\
Percentage variance explained & $52.3 \%$ & $31.5 \%$ & $14.4 \%$ \\
\hline
\end{tabular}

variance. This component was heavily weighted by DOC, TC, OTC, and SMX. DOC, TC, and SMX have been detected in waste water of hospital and in effluent of municipal wastewater treatment plant (Pena et al. 2010; Rossmann et al. 2014). The higher concentration of TC, OTC, and SMX was reported in aquaculture (Rose and Pedersen 2005; Seyfried et al. 2010; Zhang et al. 2013). Our correlation analysis also indicated these four antibiotics were positively correlated with human or aquaculture (Table 3).

The second component was responsible for $31.5 \%$ of the total variance. This component was mainly weighted with SDZ and SMZ. SDZ and SMZ were widely used in animal and have been detected in waste water of livestock (Wei et al. 2011; Zhang et al. 2012a; Wang et al. 2014). Correlations between SDZ and density of livestock and area of feeding facilities were significantly positive. In combination with results from previous studies, the second component can be identified as the livestock contamination source. The third component was responsible for $14.4 \%$ of the total variance. The third component was solely weighed with CTC and might be defined as unknown sources.

Higher concentrations of antibiotics were detected in June in the locations near intensive aquaculture areas, which might be released from aquaculture ponds in the watershed. Approximately $200 \mathrm{~km}^{2}$ of freshwater aquaculture ponds existed in the Tiaoxi basin. Studies have reported that the maximum concentrations of antibiotics can reach 426-2616 mg kg-1 in sediment samples of aquaculture ponds (Le and Munekage 2004). It is revealed that mariculture made a great contribution to antibiotics pollution in Liaodong Bay (Jia et al. 2011). Many sluice dams were constructed on the tributaries of Tiaoxi River and usually closed in low flow condition. As a result, the tributaries water with a high antibiotic concentration was kept from flowing into the mainstem of Tiaoxi River. The variation of antibiotic concentrations in September and March can be linked to the usage patterns, since aquaculture usually starting from April when the temperature is above $18{ }^{\circ} \mathrm{C}$ in the Tiaoxi watershed.

Hot spots of antibiotic contamination

Hot-spot mapping was considered as an efficient management technique at the watershed scale and has been carried out in research on fecal pollution (Jent et al. 2013) and heavy metal contamination (Li et al. 2004). 
Based on the measuring results, we have established that diffusive sources linked with wastewater from domestic sources, livestock farming, and aquaculture ponds were the potential pollution sources of antibiotics in the Tiaoxi watershed. Using results of correlation analysis, a hot-spot map of antibiotic pollution is created by extracting area of sensitive land uses (aquaculture ponds, feeding facilities, developed area, and barren) that are positively correlated with in-stream antibiotics in the Tiaoxi watershed and illustrated in Fig. 4. The method of hot-spot mapping is particularly suitable for pollution control in watershed where the non-point pollution is the dominant source. This hot-spots map will facilitate environmental agencies to manage and control antibiotic pollution by providing the source information. The hot spots identified on the map can assist further investigations to determine the exact location and loading of the specific contaminant sources. The stream segments downstream of hot spots need to be monitored with higher frequency, especially during the critical wet/ dry season. These maps can help in revealing the patterns of antibiotic contamination in watersheds by integrating multiple sources of spatial information in a visually compelling form.

\section{Conclusions}

Concentrations of four tetracyclines and three sulfonamides in surface water samples from the Tiaoxi watershed were detected. Maximum concentrations of TC, OTC, and SMX in several sites exceeded their corresponding PNEC values. The contamination of antibiotics in surface water was more serious in wet season (June) with the peak concentration up to microgram per liter, which indicated that a large amount of antibiotics discharge into the Tiaoxi River with runoff. Significant correlations of target antibiotics with explanatory variables were observed and source identification analysis using PCA separated antibiotics into three categories. The results suggested that DOC, TC, OTC, and SMX were mainly from aquaculture and domestic pollution; SDZ and SMZ mainly from husbandry; whereas CTC might from other unaccounted sources. Since concentrations of DOC, TC, OTC, and SMX were considerably high in those sites where the aquaculture is intensive, flood, or drainage from aquaculture ponds was identified as a dominant source of antibiotics contamination in the Tiaoxi watershed during wet season. Based on the statistical analysis, we created a hot-spot map which can

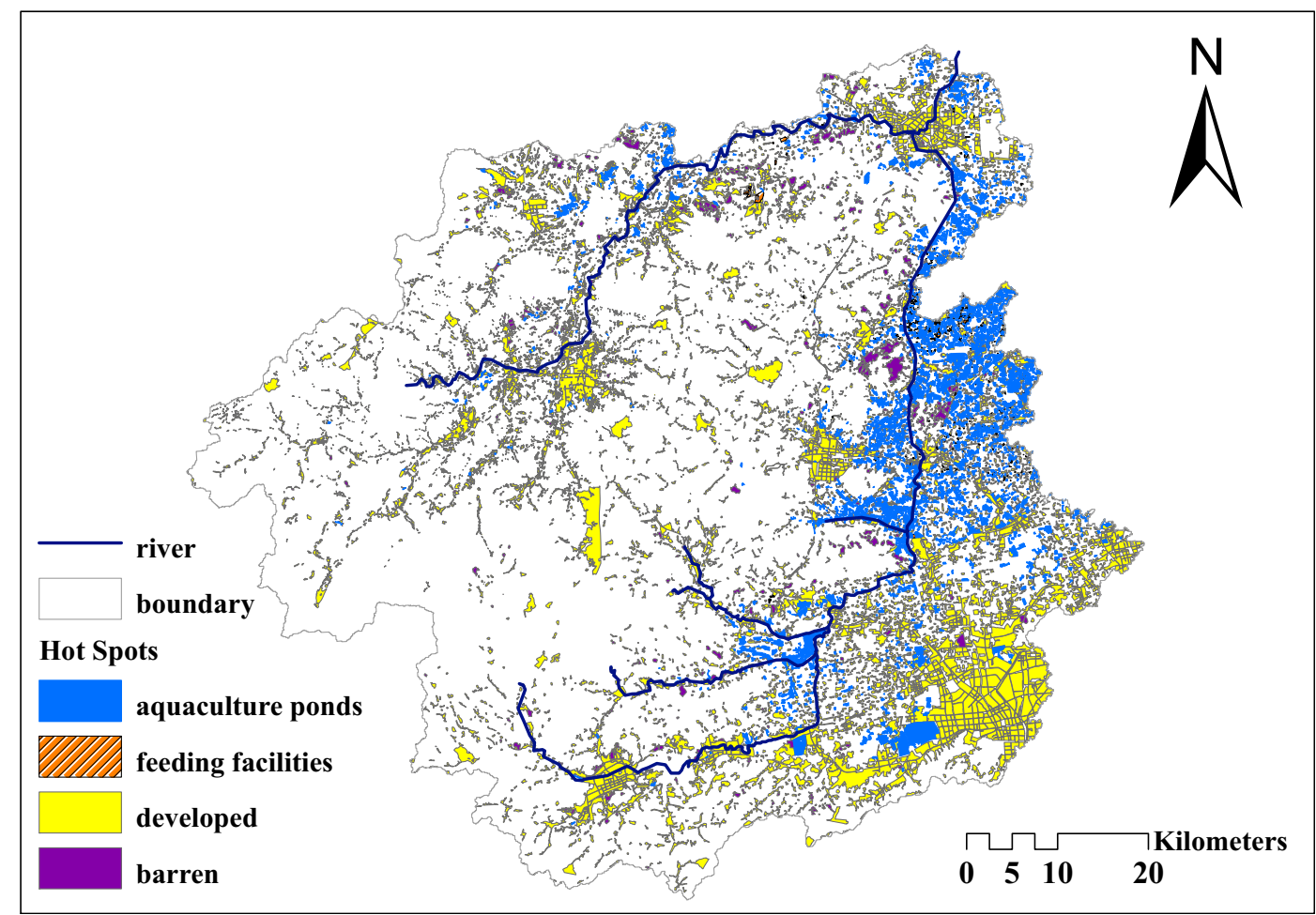

Fig. 4 Map of hot spots in the Tiaoxi watershed. Sources of antibiotic pollution are shown in color 
facilitate management and control of antibiotic pollution. Combining land-use analysis with multi-variable statistics provides an effective approach of sources identification in watersheds with multiple diffuse sources of antibiotic pollution.

Acknowledgments This study was financially supported by the National Natural Science Foundation of China (41371313, 41271506, and 41230858) and the Key Research Program of Chinese Academy of Sciences (KZZD-EW-14).

\section{References}

Burkhardt, M., Stamm, C., Waul, C., Singer, H., \& Muller, S. (2005). Surface runoff and transport of sulfonamide antibiotics and tracers on manured grassland. Journal of Environmental Quality, 34, 1363-1371.

Chen, Y., Zhang, H., Luo, Y., \& Song, J. (2012). Occurrence and dissipation of veterinary antibiotics in two typical swine wastewater treatment systems in East China. Environmental Monitoring and Assessment, 184, 2205-2217.

Davis, J. G., Truman, C. C., Kim, S. C., Ascough, J. C., \& Carlson, K. (2006). Antibiotic transport via runoff and soil loss. Journal of Environmental Quality, 35, 2250-2260.

Eguchi, K., Nagase, H., Ozawa, M., Endoh, Y. S., Goto, K., Hirata, K., et al. (2004). Evaluation of antimicrobial agents for veterinary use in the ecotoxicity test using microalgae. Chemosphere, 57, 1733-1738.

Ferrari, B., Mons, R., Vollat, B., Fraysse, B., Paxēaus, N., Giudice, R. L., et al. (2004). Environmental risk assessment of six human pharmaceuticals: are the current environmental risk assessment procedures sufficient for the protection of the aquatic environment? Environmental Toxicology and Chemistry, 23, 1344-1354.

Galvidis, I., Lapa, G., \& Burkin, M. (2015). Group determination of 14-membered macrolide antibiotics and azithromycin using antibodies against common epitopes. Analytical Biochemistry, 468, 75-82.

Halling-Sorensen, B., Lutzhoft, H. C. H., Andersen, H. R., \& Ingerslev, F. (2000). Environmental risk assessment of antibiotics: comparison of mecillinam, trimethoprim and ciprofloxacin. Journal of Antimicrobial Chemotherapy, 46, 53-58.

Han, Y. M., Peixuan, D., Junji, C., \& Posmentier, E. S. (2006). Multivariate analysis of heavy metal contamination in urban dusts of Xi'an, Central China. Science of the Total Environment, 355, 176-186.

Jent, J. R., Ryu, H., Toledo-Hernandez, C., Domingo, J. W. S., \& Yeghiazarian, L. (2013). Determining hot spots of fecal contamination in a tropical watershed by combining land-use information and meteorological data with source-specific assays. Environmental Science \& Technology, 47, 57945802.

Jia, A., Hu, J. Y., Wu, X. Q., Peng, H., Wu, S. M., \& Dong, Z. M. (2011). Occurrence and source apportionment of sulfonamides and their metabolites in liaodong bay and the adjacent liao river basin, North China. Environmental Toxicology and Chemistry, 30, 1252-1260.

Jiang, L., Hu, X. L., Yin, D. Q., Zhang, H. C., \& Yu, Z. Y. (2011). Occurrence, distribution and seasonal variation of antibiotics in the Huangpu River, Shanghai, China. Chemosphere, 82, $822-828$.

Kang, J. H., Lee, S. W., Cho, K. H., Ki, S. J., Cha, S. M., \& Kim, J. H. (2010). Linking land-use type and stream water quality using spatial data of fecal indicator bacteria and heavy metals in the Yeongsan river basin. Water Research, 44, 4143-4157.

Kay, P., Blackwell, P. A., \& Boxall, A. B. A. (2005). A lysimeter experiment to investigate the leaching of veterinary antibiotics through a clay soil and comparison with field data. Environmental Pollution, 134, 333-341.

Kemper, N. (2008). Veterinary antibiotics in the aquatic and terrestrial environment. Ecological Indicators, 8(1), 1-13.

Kim, S.-C., Davis, J. G., Truman, C. C., Ascough II, J. C., \& Carlson, K. (2010). Simulated rainfall study for transport of veterinary antibiotics - mass balance analysis. Journal of Hazardous Materials, 175, 836-843.

Kolpin, D. W., Furlong, E. T., Meyer, M. T., Thurman, E. M., Zaugg, S. D., Barber, L. B., et al. (2002). Pharmaceuticals, hormones, and other organic wastewater contaminants in US streams, 1999-2000: a national reconnaissance. Environmental Science \& Technology, 36, 1202-1211.

Kreuzig, R., Holtge, S., Brunotte, J., Berenzen, N., Wogram, J., \& Schulz, R. (2005). Test-plot studies on runoff of sulfonamides from manured soils after sprinkler irrigation. Environmental Toxicology and Chemistry, 24, 777-781.

Kummerer, K. (2001). Drugs in the environment: emission of drugs, diagnostic aids and disinfectants into wastewater by hospitals in relation to other sources - a review. Chemosphere, 45, 957-969.

Kummerer, K. (2009). Antibiotics in the aquatic environment-a review-part I. Chemosphere, 75, 417-434.

Larsson, D. G. J., de Pedro, C., \& Paxeus, N. (2007). Effluent from drug manufactures contains extremely high levels of pharmaceuticals. Journal of Hazardous Materials, 148, 751-755.

Le, T. X., \& Munekage, Y. (2004). Residues of selected antibiotics in water and mud from shrimp ponds in mangrove areas in Viet Nam. Marine Pollution Bulletin, 49, 922-929.

Lee, L. S., Carmosini, N., Sassman, S. A., Dion, H. M., \& Sepulveda, M. S. (2007). Agricultural contributions of antimicrobials and hormones on soil and water quality. Advances in Agronomy, 93, 1-68.

Li, X. D., Lee, S. L., Wong, S. C., Shi, W. Z., \& Thornton, L. (2004). The study of metal contamination in urban soils of Hong Kong using a GIS-based approach. Environmental Pollution, 129, 113-124.

Luo, Y., Xu, L., Rysz, M., Wang, Y. Q., Zhang, H., \& Alvarez, P. J. J. (2011). Occurrence and transport of tetracycline, sulfonamide, quinolone, and macrolide antibiotics in the Haihe River basin, China. Environmental Science \& Technology, 45, 1827-1833.

Lutzhoft, H. C. H., Halling-Sorensen, B., \& Jorgensen, S. E. (1999). Algal toxicity of antibacterial agents applied in Danish fish farming. Archives of Environmental Contamination and Toxicology, 36, 1-6.

Moreno-Bondi, M. C., Marazuela, M. D., Herranz, S., \& Rodriguez, E. (2009). An overview of sample preparation procedures for LC-MS multiclass antibiotic determination in 
environmental and food samples. Analytical and Bioanalytical Chemistry, 395, 921-946.

Pena, A., Paulo, M., Silva, L. J. G., Seifrtova, M., Lino, C. M., \& Solich, P. (2010). Tetracycline antibiotics in hospital and municipal wastewaters: a pilot study in Portugal. Analytical and Bioanalytical Chemistry, 396, 2929-2936.

Rose, P. E., \& Pedersen, J. A. (2005). Fate of oxytetracycline in streams receiving aquaculture discharges: model simulations. Environmental Toxicology and Chemistry, 24, 40-50.

Rossmann, J., Schubert, S., Gurke, R., Oertel, R., \& Kirch, W. (2014). Simultaneous determination of most prescribed antibiotics in multiple urban wastewater by SPE-LC-MS/MS. Journal of Chromatography. B, Analytical Technologies in the Biomedical and Life Sciences, 969, 162-170.

Seyfried, E. E., Newton, R. J., Rubert, K. F., Pedersen, J. A., \& McMahon, K. D. (2010). Occurrence of tetracycline resistance genes in aquaculture facilities with varying use of oxytetracycline. Microbial Ecology, 59, 799-807.

Sharma, H., Jain, V. K., \& Khan, Z. H. (2007). Characterization and source identification of polycyclic aromatic hydrocarbons (PAHs) in the urban environment of Delhi. Chemosphere, 66, 302-310.

Sofowote, U. M., McCarry, B. E., \& Marvin, C. H. (2008). Source apportionment of PAH in Hamilton harbour suspended sediments: comparison of two factor analysis methods. Environmental Science \& Technology, 42, 6007-6014.

Thiele-Bruhn, S. (2003). Pharmaceutical antibiotic compounds in soils - a review. Journal of Plant Nutrition and Soil Science, 166, 145-167.

Vazquez-Roig, P., Andreu, V., Blasco, C., \& Pico, Y. (2012). Risk assessment on the presence of pharmaceuticals in sediments, soils and waters of the Pego-Oliva marshlands (Valencia, eastern Spain). Science of the Total Environment, 440, 24-32.

Wang, N., Guo, X. Y., Xu, J., Kong, X. J., Gao, S. X., \& Shan, Z. J. (2014). Pollution characteristics and environmental risk assessment of typical veterinary antibiotics in livestock farms in southeastern China. Journal of Environmental Science and Health, Part B, 49, 468-479.

Wei, R. C., Ge, F., Huang, S. Y., Chen, M., \& Wang, R. (2011). Occurrence of veterinary antibiotics in animal wastewater and surface water around farms in Jiangsu Province, China. Chemosphere, 82, 1408-1414.

Wiegel, S., Aulinger, A., Brockmeyer, R., Harms, H., Loffler, J., Reincke, H., et al. (2004). Pharmaceuticals in the river Elbe and its tributaries. Chemosphere, 57, 107-126.

Xu, W. H., Yan, W., Li, X. D., Zou, Y. D., Chen, X. X., Huang, W. X., et al. (2013). Antibiotics in riverine runoff of the Pearl River Delta and Pearl River estuary, China: concentrations, mass loading and ecological risks. Environmental Pollution, 182, 402-407.

Zhang, R. J., Zhang, G., Tang, J. H., Xu, W. H., Li, J., Liu, X., et al. (2012a). Levels, spatial distribution and sources of selected antibiotics in the East River (Dongjiang), South China. Aquatic Ecosystem Health \& Management, 15, 210-218.

Zhang, R. J., Zhang, G., Zheng, Q., Tang, J. H., Chen, Y. J., Xu, W. H., et al. (2012b). Occurrence and risks of antibiotics in the Laizhou Bay, China: impacts of river discharge. Ecotoxicology and Environmental Safety, 80, 208-215.

Zhang, R. Q., Ying, G. G., Su, H. C., Zhou, L. J., \& Liu, Y. S. (2013). Antibiotic resistance and genetic diversity of Escherichia coli isolates from traditional and integrated aquaculture in South China. Journal of Environmental Science and Health, Part B, 48, 999-1013.

Zou, S. C., Xu, W. H., Zhang, R. J., Tang, J. H., Chen, Y. J., \& Zhang, G. (2011). Occurrence and distribution of antibiotics in coastal water of the Bohai Bay, China: impacts of river discharge and aquaculture activities. Environmental Pollution, 159, 2913-2920.

Zuccato, E., Castiglioni, S., Bagnati, R., Melis, M., \& Fanelli, R. (2010). Source, occurrence and fate of antibiotics in the Italian aquatic environment. Journal of Hazardous Materials, 179, 1042-1048. 